\title{
Mental illness: psychiatry's phlogiston
}

Thomas Szasz State University of New York, USA

\begin{abstract}
In physics, we use the same laws to explain why airplanes fly, and why they crash. In psychiatry, we use one set of laws to explain sane behaviour, which we attribute to reasons (choices), and another set of laws to explain insane behaviour, which we attribute to causes (diseases). God, man's idea of moral perfection, judges human deeds without distinguishing between sane persons responsible for their behaviour and insane persons deserving to be excused for their evil deeds. It is hubris to pretend that the insanity defence is compassionate, just, or scientific. Mental illness is to psychiatry as phlogiston was to chemistry. Establishing chemistry as a science of the nature of matter required the recognition of the non-existence of phlogiston. Establishing psychiatry as a science of the nature of human behaviour requires the recognition of the non-existence of mental illness.

(Fournal of Medical Ethics 2001;27:297-301)
\end{abstract}

Keywords: Agency; alchemy; behaviour; cause; chemistry; dignity

"There is no error so monstrous that it fails to find defenders among the ablest men": Lord Acton.

People crave answers. Therefore, everyone may be considered a scientist, or at least a scientist manqué. The true scientist differs from the ordinary person in the depth, breadth, precision, and power of the account he or she accepts as the correct explanation for his or her observation, and in his or her willingness to revise it in the light of new evidence.

In this essay, I try to show that mental illness is to psychiatry as phlogiston was to chemistry. Establishing chemistry as a science of the nature and composition of matter required the recognition of the non-existence of phlogiston. Establishing "psychiatry" as a science of human behaviour requires the recognition that "mental illness" does not exist.

\section{A brief history of phlogiston}

Chemistry began as alchemy which, in turn, was closely connected with medicine. Both Johann Joachim Becher (1635-1682) and Georg Ernst Stahl (1660-1734), two of chemistry's pioneers, were physicians, at a time when people believed that problems of health and disease were best explained in terms of the four basic Galenic humours.

One of the foremost problems early chemists tried to solve was combustion. What happens when a substance burns? Stahl proposed that all inflammable objects contained a material substance that he called "phlogiston," from the Greek word meaning "to set on fire". When a substance burned, it liberated its content of phlogiston into the air, which was believed to be chemically inert. The phlogiston theory dominated scientific thinking for more than a century.

It was observed, however, that after a piece of metal was burned (oxidised), it weighed more than it did before, whereas according to the phlogiston theory it should have weighed less. This inconsistency was resolved by postulating that phlogiston was an immaterial principle rather than a material substance; alternatively, it was suggested that phlogiston had a negative weight. When chemists discovered hydrogen, they believed it to be pure phlogiston.

The phlogiston theory was overthrown by the work of Antoine Laurent Lavoisier (1743-1794). He named the fraction of air that supported combustion "oxygen," a term derived from the Greek words meaning "acid-producing", because he thought, wrongly, that oxygen was a necessary component of all acids. The major fraction of air that does not support combustion he called "azote," from the Greek words meaning "no life". Azote is now called "nitrogen". In a historic paper, titled "Memoir on the nature of the principle which combines with metals during their calcination [oxidation] and which increases their weight", delivered at the French Royal Academy of Sciences in 1775, and published in 1778, Lavoisier disproved the phlogiston theory and laid the framework for understanding chemical reactions as combinations of elements which form new materials. ${ }^{3}$

Once names and theories gain wide acceptance, they exercise a powerful influence on those inculcated to believe that their existence forms an integral part of the way the world is-in short, "reality". New observations are then "seen" through the lens of the prevailing system of mental optics. For example, Joseph Priestley (1733-1804), the great English chemist, could not relinquish the phlogiston theory, even after he himself had discovered oxygen and after Lavoisier's work swept the scientific world. He continued to view oxygen as "dephlogisticated air". In a pamphlet titled, "Considerations on the doctrine of phlogiston and the decomposition of water", published in 1796, he referred to Lavoisier's followers as "Antiphlogistians", and complained: "On the whole, I cannot help saying, that it appears to me not a little extraordinary, that a theory so new, and of such importance, overturning every thing that was 
thought to be the best established chemistry, should rest on so very narrow and precarious a foundation".

\section{A brief history of mental illness}

While alchemy changed into chemistry, the soul changed into the mind and sins became sicknesses (of the mind). The early alienists (physicians who claimed special expertise regarding the diagnosis and treatment of mental illnesses) frankly acknowledged this metamorphosis. However, instead of recognising that it was an early manifestation of a move from a religious to a secular outlook on human behaviour, they attributed it to scientific advances and believed that a set of new brain diseases had been discovered which they called "mental diseases".

What Georg Ernst Stahl was to early chemistry and phlogiston, Benjamin Rush (1745-1813) was to early psychiatry and mental illness. Rush was a physician and an American patriot. He signed the Declaration of Independence, served as physician general of the Continental Army and as professor of physic and dean of the University of Pennsylvania medical school. In 1812, he published Medical Inquiries and Observations upon the Diseases of the Mind, the first American textbook of psychiatry. Rush is the undisputed father of American psychiatry: his portrait adorns the official seal of the American Psychiatric Association. In 1774, he declared: "Perhaps hereafter it may be as much the business of a physician as it is now of a divine to reclaim mankind from vice". ${ }^{\text {? }}$

To distinguish himself from the doctor of divinity, the doctor of medicine could not simply claim that he was protecting people from sin, or vice as Rush put it. Badness remained, after all, a moral concept. As medical scientist, the physician had to claim that badness was madness, that his object of study was not the immaterial soul or "will", but a material object, a bodily disease. That is precisely what Rush did. His following assertions illustrate that he did not discover that certain behaviours are diseases, he decreed that they are: "Lying is a corporeal disease. / Suicide is madness. / Chagrin, shame, fear, terror, anger, unfit[ness] for legal acts, are transient madness." " Today, some of these and many other unwanted human behaviours are widely accepted as real diseases, their existence ostensibly supported by scientific discoveries.

\section{The congenital epistemological error of psychiatry}

Modern natural science rests on laws uninfluenced by human desire or motivation. We use the same physical laws to explain why airplanes fly and crash, the same chemical laws to explain the therapeutic and toxic effects of drugs, and the same biological laws to explain how healthy cells maintain the integrity of the organism and how these cells can become cancerous and destroy the host. We do not have one set of medical theories to explain normal bodily functions, and another set to explain abnormal bodily functions.
In psychiatry, the situation is exactly the reverse. We have one set of principles to explain the functioning of the mentally healthy person, and another set to explain the functioning of the mentally ill person: we attribute acceptable, "rational" behaviours to reasons, unacceptable, "irrational" behaviours to causes. The mentally healthy person is viewed as an active agent: he makes decisions, he chooses, for example, to marry his sweetheart. In contrast, the mentally ill person is viewed as a passive body: as patient, he is the victim of injurious biological, chemical or physical processes acting upon his body, that is, diseases (of his brain), for example, of an "irresistible impulse" to kill. "The epileptic neurosis", wrote Sir Henry Maudsley (1835-1918), the founder of modern British psychiatry, "is apt to burst out into a convulsive explosion of violence. ... To hold an insane person responsible for not controlling an insane impulse ... is in some cases just as false ... as it would be hold a man convulsed by strychnia responsible for not stopping the convulsions." It is a false analogy. Killing is a coordinated act. Convulsion is an uncoordinated contraction of muscles, an event.

Because explanations of human behaviour influence law and social policy much more pervasively and profoundly than do explanations of natural events, the mental illness theory of behaviour has far-reaching implications for virtually every aspect of our daily life. Law professor Michael S Moore's following statement expresses a view now widely shared by lawyers, psychiatrists, and the general public:

"Since mental illness negates our assumption of rationality, we do not hold the mentally ill responsible. It is not so much that we excuse them from a prima facie case of responsibility; rather, by being unable to regard them as fully rational beings, we cannot affirm the essential condition to viewing them as moral agents to begin with. In this the mentally ill join (to a decreasing degree) infants, wild beasts, plants, and stones-none of which are responsible because of the absence of any assumption of rationality." 10

We are proud that we have all but abolished our prejudiced beliefs about the differences between the human natures of men and women or whites and blacks. At the same time, we are even prouder that we have created a set of psychiatric beliefs about the differences between the neuroanatomical and neurophysiological natures of the sane and the insane, the mentally healthy and the mentally ill. Oxidation, a real process, explains combustion better than does phlogiston, a non-existent substance. Attributing all human actions to choice, the basic building block of our social existence, explains human behaviour better than attributing certain (disapproved) actions to mental illness, a nonexistent disease.

A cause may operate momentarily or over time. A stationary billiard ball begins to move the moment another ball hits it. A broken hip makes walking impossible for days or weeks. Hence, it is not 
enough to say that a person pushes another in front of a subway train because he has schizophrenia and that schizophrenia is due to abnormal neurochemical processes in the brain. We must also explain why he did so when he did so. The alleged condition, "schizophrenia", cannot do that, inasmuch as it has existed before the commission of the homicide and is said to exist in millions of persons who engage in no violence.

A person opens his umbrella when he goes out into the rain, because he does not want to get wet. A person pushes another in front of a subway train not because he "has" schizophrenia or because schizophrenia "makes" him do it; he does it because, like the man who opens an umbrella, he wants to improve his existence. We can explain a person's seemingly irrational act too by attributing it to a reason, for example, wanting to attract attention to himself or wanting to escape responsibility for housing and feeding himself.

In short, regardless of the condition of an "irrationally" acting person's brain, he remains a moral agent who has reasons for his actions: like all of us, he chooses or wills what he does. People with brain diseases-amyotrophic lateral sclerosis, multiple sclerosis, Parkinsonism, glioblastoma-are persons whose actions continue to be governed by their desires or motives. The illness limits their freedom of action, but not their status as moral agents.

\section{Answering objections}

According to psychiatric theory, certain actions by certain people ought to be attributed to causes, not reasons. When and why do we seek a causal explanation for personal conduct? When we consider the actor's behaviour unreasonable and do not want to blame him for it. We then look for an excuse masquerading as an explanation, rather than simply an explanation that neither exonerates nor incriminates.

There is a crucial difference between explaining the movement of objects and explaining the behaviour of persons. Our explanation of the movement of planets is (today) devoid of moral implications, whereas our explanation of the behaviour of persons is heavily freighted with moral implications. As a rule, we hold persons responsible for what they do, and do not hold them responsible for what happens to them. Agreement and disagreement, approval and disapproval, praise and blame, are tacit elements of the vocabulary we use to explain personal conduct.

Holding a person responsible for his act is not the same as blaming or praising him for it: it means only that we regard him as an actor or moral agent. Blame or praise expresses judgment of his act, or of him as a person, as wicked or virtuous; in either case, it does not gainsay his authorship of his behaviour. Conversely, holding a person not responsible for his act by reason of mental illness means that we do not regard him as a (full-fledged) actor or moral agent; instead, we regard him as a victim of his "illness". Although we pronounce such a person "not guilty" of the injurious act he has committed (say, murder), we nevertheless regard his act as deplorable, and we nevertheless deprive him of liberty. We have not proved that he lacks reasons for his behaviour. We have merely offered a different explanation for his behaviour (based on causes, not reasons), and provided a different justification for detaining him (based on medical rather than legal considerations). In short, the insanity plea, the insanity verdict, and the insanity disposition form a tactical package which we use if we do not want to regard an actor as a moral agent and prefer to "treat" him as a mental patient. ${ }^{11}$

It is a mistake to believe that offering an excuseexplanation for an act is tantamount to showing that the actor has no reasons for his action. Offering an excuse for doing X-"God's voice commanded $m e$ "-is not the same as not having reasons for doing $\mathrm{X}$. To the contrary: what we have shown is not that the actor has no reasons, but that his reasons are wrongheaded-"deluded", "mad", "insane". We conclude that his actions are caused by his being deluded, mad, insane. But we have not proven anything of the sort; we have postulated it.

Prior to the eighteenth century, people who committed heinous crimes and acted strangely were thought to resemble wild animals. Hence, the antiquated "wild beast" model of insanity and the defence based on it. Seeing the "deluded" person whose "voices" command him to kill as similar to an automaton or robot-that is, an object that performs human-like motions but is not human-is a modern idea. Accepting the assertion of a "schizophrenic" that he killed his wife because God's voice commanded him to do so is not evidence of the validity of the explanation. In my view, such a person kills his victim because that is what he wants to do, but he disavows his intention; instead of acknowledging his motive, he defines himself as a helpless slave obeying orders. As I have shown elsewhere, the so-called voices some mentally ill people "hear" are their own inner voices or self conversations, whose authorship they disown. ${ }^{10}$ This interpretation is supported by the fact that neuroimaging studies of hallucinating persons reveal activation of Broca's (speech) area, not activation of Wernicke's (auditory) area. ${ }^{13}$

\section{Slave-like objects}

The "mental patient" who attributes his misdeed to "voices"-that is, to an agent, other than himself, whose authority is irresistible-is not the victim of an irresistible impulse; he is an agent, a victimiser rationalising his action by attributing it to an irresistible authority. The analogy between a person who "hears voices" and an object, say a computer programmed to play chess, responding to information, is false. Mental patients responding to the commands of "voices" resemble persons responding to the commands of authorities with irresistible powers, exemplified by "suicide-bombers" who martyr themselves in the name of God. Both types of persons are moral agents, albeit both types represent themselves as slave-like objects, executing 
the wills of others (often identified as God or the devil). These representations are dramatic metaphors that actors and audience alike may, or may not, interpret as literal truths. It is not by accident that, in all the psychiatric literature, there is not a single account of voices that command a schizophrenic to be especially kind to his wife. That is because being kind to one's wife is not the sort of behaviour to which we want to assign a causal (psychiatric) explanation.

The facile, but fallacious, equation of mental illness with mental incompetence precludes an empirically valid and logically consistent psychiatric explanation of behaviour. For example, a patient's belief that his wife is a witch may be a metaphor (for thinking that she is a bad person), or a "delusion" (similar to a false/self-serving/destructive religious belief, such as Abraham's belief that it was God's wish that he sacrifice Isaac). We do not view the person who acts on the basis of false information (say, a wrong timetable) as having no reason for his action. Similarly, we ought not to view the person who acts on the basis of false belief ("delusion") as having no reason for his action. We may, as I noted, want to treat such a person as not blameworthy. That is not, however, the same as asserting that he acts without reason or that his deed is "meaningless" or "senseless," the terms typically used to dismiss the meaning or sense of heinous crimes.

\section{Domination-Submission}

The typical mental patient is a conscious adult who has not been declared legally incompetent. "Seriously mentally disordered patients neither lack insight, nor is their competency impaired to the degree previously believed," writes George Hoyer, a professor at the Institute of Community Medicine, University of Tromsoe, Norway. ${ }^{4}$ Moreover, mental patients are regularly considered competent to do some things, but not others, for example, competent to live independently, but not competent to reject psychiatric drug treatment; competent to stand trial, but not competent to represent themselves in court; competent to vote, but not competent to leave the hospital.

Young children and senile persons engage, or may want to engage, in actions for which their reasons may be poor, indeed. But, again, that does not mean their actions are not motivated by reasons. Bringing up children, "civilising primitive people," forcibly converting people to the "true faith", rehabilitating criminals, and many other relations of dominationsubmission rest on the premise that the subject people's reasons for action are immature or erroneous and need to be "corrected", to enable them to enjoy "true freedom". As long as relations between psychiatrists and mental patients (especially "psychotics") rest on domination-submission, the idea of mental illness serves a similar set of functions: it explains the inferior person's (mis)behaviour, exempts him from blame, and justifies his forcible control by psychiatrists.

"In The Myth of Mental Illness", observed University of Sussex professor Rupert Wilkinson, "the psychiatrist Thomas Szasz ... did identify an important process: we might call it 'a chase through language'.... Our better natures, it seems, introduce words to promote compassion-but residual needs to despise and distance weakness will not be stopped. ... The terminology of mental illness substitutes labels of incompetence for labels of moral deficiency, and in a secular society this is no gift." ${ }^{14}$

\section{Conclusions}

The word "mind" and the derivative term "mental illness" name two of our most important, but most confused and confusing, ideas. The Latin word "mens" means not only mind but also intention and will, a signification still present in our use of the word "mind" as a verb. Because we attribute intention only to intelligent, sentient beings, minding implies agency.

The concept of mind-as the attribution of moral agency to some persons but not others-plays a crucial role in moral philosophy, law, and psychiatry. Infants and demented old persons cannot communicate by language and are therefore typically excluded from the category of moral agents. In the past, some persons able to communicate by language-for example, slaves and women-were also denied the status of moral agents. Today, many children and mental patients-possessing the ability to communicate-are denied that status. The point is that attributing or refusing to attribute moral agency to the Other is a matter of both fact and tactic-a decision that depends not only on the Other's abilities, but also on our attitude toward him. To be recognised as a moral agent, an individual must be able and willing to function as a responsible member of society, and society must be willing to ascribe that capacity and status to him.

The dependence of moral agency on mindedness renders the judgment of impaired mindedness-that is, the diagnosis of "mental illness"-of paramount legal and social significance. Two common tactics characteristic of our age deserve special mention in this connection. One is treating persons as incompetent when in fact they are not-harming them under the guise of helping them. The other is treating persons as victims when in fact they are victimisers (of themselves or others)-excusing them of responsibility for their behaviour (blaming their self injury or injury of others on innocent third parties).

Paradoxically, the old, prescientific-religious explanation of human behaviour is more faithful to the facts than the modern, scientific-psychiatric explanation of it. When man invents the Perfect Judge and calls him "God," he creates an arbiter who does not distinguish between two kinds of conduct-one rational, for which man is responsible, and another irrational, for which he is not. Being held responsible for our actions is what renders us fully human: it is the glory with which God endows everyone, and the burden $\mathrm{He}$ imposes on everyone. Erroneous explanations of the material world lead to physical catastrophes, false explanations of the human condition, to moral catastrophes. 
Thomas Szasz, MD, is Professor of Psychiatry Emeritus, Upstate Medical University, State University of New York, Syracuse, New York, USA.

\section{References}

1 Acton JEED. In: Fears JR, ed. Essays in the study and writing of history [vol3]. Indianapolis: Liberty Classics, 1988: 550.

2 Alexander GJ, Scheflin AW. Law and mental disorder. Durham NC: Carolina Academic Press, 1998.

3 Do: Carolina Academic Press, 1998. tion. Oxford: Blackwell, 1993.

tion. Oxford: Blackwell, 1993 .
Hoyer G. On the justification for civil commitment. Acta Hoyer G. On the justification for civil
Psychiatrica Scandinavica,2000;101:65-71.

5 Priestley J. Considerations on the doctrine of phlogiston and the decomposition of water. Philadelphia: Thomas Dobson, 1796. www.web.lemoyne.edu/ giunta/priestley.htm

6 Rush B. Medical inquiries and observations upon the diseases of the mind [1812]. New York: Macmillan-Hafner Press, 1962.
7 Rush B. Letter to Granville Sharp, July 9, 1774. In: Woods JA, ed. The correspondence of Benjamin Rush and Granville Sharp, 1773-1809. Fournal of American Studies 1967;1:8.

8 Rush B. Lectures on the medical jurisprudence of the mind [1810]. In: Corner GW, ed. The autobiography of Benjamin Rush: his "travels through life" together with his "commonplace book for 1789-1812". Princeton: Princeton University Press, 1948: 350.

9 Maudsley H. In: Reynolds EH, Trimble MR, eds. Epilepsy and psychiatry. London: Churchill Livingstone, 1981: 4.

10 Moore MS. Some myths about 'mental illness'. Archives of General Psychiatry 1975; 32:1483-97.

11 Szasz TS. Insanity: the idea and its consequences. New York: Wiley, 1987 .

12 Szasz TS. 'Audible thoughts' and 'speech defect' in schizophrenia: a note on reading and translating Bleuler. British Fournal of Psychiatry 1996;168:533-5.

13 Szasz TS. The meaning of mind: language, morality, and neuroscience. Westport, CT: Praeger, 1996: 124-9.

14 Wilkinson R. Word-choosing: sources of a modern obsession. Encounter 1982;59:80-7.

\section{News and notes \\ European Master in Bioethics}

The next European Master in Bioethics course, a postgraduate programme designed to meet the needs of health care professionals who want to combine in-depth study of bioethical issues with their current professional work, begins in March 2002 in Nijmegen, the Netherlands.

The course runs for two years and there are four residential sessions: March 2002 in Nijmegen, September 2002 in Basel, Switzerland, March 2003 in Leuven, Belgium and September 2003 in Padova, Italy.
The course fee is 15,000 Euro.

Every application should be accompanied by a curriculum vitae and the candidate's reasons for choosing to apply for the programme.

For further information contact either Katrien Ruytjens: tel: + 32163369 51; fax: + 32163369 52; email: Katrien.ruytjens@med.kuleuven.ac.be; www.masterbioethics.com or Inez Uerz: tel: + 3124 36153 20; fax: + 312435402 54; email: i.uerz@efg.kun.nl 